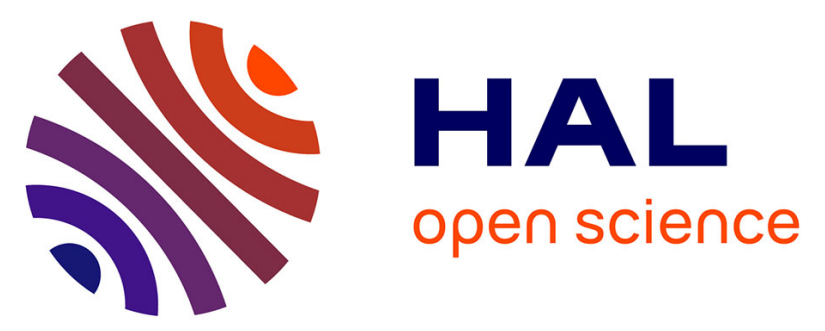

\title{
Beyond simple AB diblock copolymers: application of bifunctional and trifunctional RAFT agents to PISA in water
}

Gaëlle Mellot, Patricia Beaunier, Jean-Michel Guigner, Laurent Bouteiller, Jutta Rieger, François Stoffelbach

\section{To cite this version:}

Gaëlle Mellot, Patricia Beaunier, Jean-Michel Guigner, Laurent Bouteiller, Jutta Rieger, et al.. Beyond simple $\mathrm{AB}$ diblock copolymers: application of bifunctional and trifunctional RAFT agents to PISA in water. Macromolecular Rapid Communications, 2019, 25 (12), 10.1002/marc.201800315. hal-02404754

\section{HAL Id: hal-02404754 \\ https: / hal.sorbonne-universite.fr/hal-02404754}

Submitted on 11 Dec 2019

HAL is a multi-disciplinary open access archive for the deposit and dissemination of scientific research documents, whether they are published or not. The documents may come from teaching and research institutions in France or abroad, or from public or private research centers.
L'archive ouverte pluridisciplinaire HAL, est destinée au dépôt et à la diffusion de documents scientifiques de niveau recherche, publiés ou non, émanant des établissements d'enseignement et de recherche français ou étrangers, des laboratoires publics ou privés. 
DOI: 10.1002/marc.((insert number)) ((or ppap., mabi., macp., mame., mren., mats.))

\title{
Communication
}

\section{Beyond simple AB diblock copolymers: application of bifunctional and trifunctional RAFT agents to PISA in water ${ }^{\mathrm{a}}$}

Gaëlle Mellot, Patricia Beaunier, Jean-Michel Guigner, Laurent Bouteiller, Jutta Rieger* and François Stoffelbach*

G. Mellot, Dr. L. Bouteiller, Dr. J. Rieger, Dr. F. Stoffelbach

Sorbonne Université, CNRS, Institut Parisien de Chimie Moléculaire, UMR 8232, Equipe chimie des polymères F-75252 Paris Cedex 05 (France).

jutta.rieger@upmc.fr; francois.stoffelbach@upmc.fr

P. Beaunier

Sorbonne Université, CNRS, Laboratoire de Réactivité de Surface, UMR 7197, F-75252 Paris

Cedex 05 (France).

Dr J.-M. Guigner

Sorbonne Université, CNRS, Institut de Minéralogie, de Physique des Matériaux et de Cosmochimie, UMR 7590 - IRD - MNHN, F-75005 Paris (France)

\begin{abstract}
The influence of the macro-RAFT agent architecture on the morphology of the self-assemblies obtained by aqueous RAFT dispersion polymerization in PISA is studied by comparing amphiphilic $\mathrm{AB}$ diblock, $(\mathrm{AB})_{2}$ triblock and triarm-star shaped $(\mathrm{AB})_{3}$ copolymers, constituted of $N, N$-dimethylacrylamide $(\mathrm{DMAc}=\mathrm{A})$ and diacetone acrylamide $(\mathrm{DAAm}=\mathrm{B})$. Symmetrical triarm $(\mathrm{AB})_{3}$ could be synthesized for the first time in a PISA process. Spheres and higher order morphologies, such as worms or vesicles, could be obtained for all types of architectures and the parameters that determine their formation have been studied. In particular, we found that the total $D P_{n}$ of the PDMAc and the PDAAm segments, i.e. same overall molar mass, at the same $M_{\mathrm{n}}(\mathrm{PDMAc}) / M_{\mathrm{n}}(\mathrm{PDAAm})$ ratio, rather than the individual length of the arms determined
\end{abstract}

\footnotetext{
${ }^{\text {a }}$ Supporting Information is available online from the Wiley Online Library or from the author.
} 
the morphologies for the linear $(\mathrm{AB})_{2}$ and star shaped $(\mathrm{AB})_{3}$ copolymers obtained by using the bi- and trifunctional macro-RAFT agents.

\section{FIGURE FOR TOC}

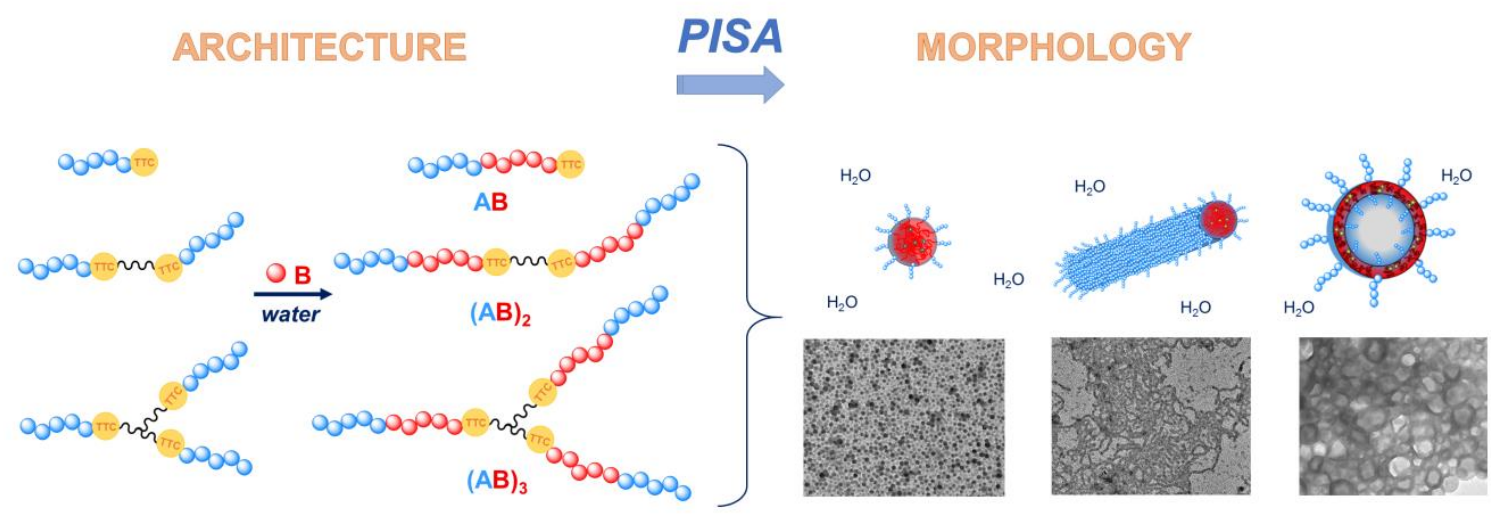

\section{Text for TOC}

Self-assemblies of linear $\mathrm{AB}$ diblock, $(\mathrm{AB})_{2}$ triblock and $(\mathrm{AB})_{3}$ triarm star shaped copolymers are prepared by PISA via aqueous RAFT dispersion polymerization. The influence of the macro-CTA architecture on the nano-objects morphology is highlighted.

\section{Introduction}

Over the past decade Polymerization-Induced Self-Assembly (PISA) in aqueous dispersed media has been largely developed. ${ }^{[1,2]}$ PISA generally involves the use of controlled/living polymerization techniques, in particular reversible addition-fragmentation chain transfer (RAFT) polymerization, ${ }^{[3]}$ which is nowadays recognized as the most powerful and versatile polymerization technique for PISA. ${ }^{[4-6]}$ In addition, first examples using "non-living" radical polymerization $^{[7]}$ or ring-opening metathesis polymerization ${ }^{[8]}$ have also been reported in PISA. In RAFT-mediated PISA a hydrophilic macromolecular chain transfer agent (macro-CTA) is 
typically chain extended with a second, less soluble monomer under heterogeneous polymerization conditions to form an amphiphilic diblock copolymer that self-assembles in the course of the polymerization. The heterogeneous process is either an emulsion polymerization, where the liquid monomer and the resulting polymer are both insoluble in the solvent, or a dispersion polymerization, where the monomer is dissolved/miscible in the solvent, but the polymer is not. PISA is not only considered as an efficient and reliable strategy to produce amphiphilic diblock copolymers but also to prepare nano-objects with controllable morphologies including spheres, worms or vesicles in high yields and at high solid contents (typically 10-40 wt\%). ${ }^{[9,10]}$ It is nowadays well established that numerous parameters, mainly the monomer concentration, the chemical nature and the respective length of the blocks have an impact on the nano-object morphology. ${ }^{[1,9-16]}$ Another important parameter that has been less considered in PISA so far, is the macromolecular architecture. ${ }^{[17]}$ Indeed, it has previously been observed for amphiphilic block copolymers synthesized in solution that the macromolecular architecture (e.g., $\mathrm{AB}$ versus symmetrical $(\mathrm{AB})_{2}$ block copolymers possessing the same overall number-average molar mass, $M_{\mathrm{n}}$, and the same $\mathrm{A} / \mathrm{B}$ ratio) had an impact on the size and the aggregation number of the resulting micelles prepared by direct dissolution of the copolymer in water. ${ }^{[18]}$ Hitherto, PISA derived assemblies are mainly based on simple diblock copolymers and only very few examples based on more complex architectures have been reported. ${ }^{[19-22]}$ In pure water, in particular, there are only a handful of reports beyond

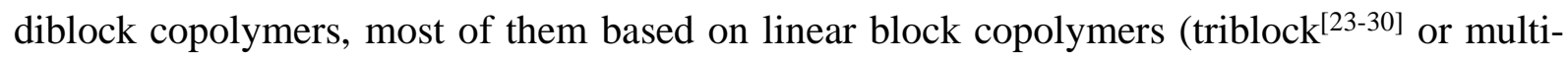
block $^{[26,31]}$ ) and to the best of our knowledge there is only one example based on a more complex Y-shape architecture $\left(\mathrm{AB}_{2}\right)$. This latter structure was formed via RAFT dispersion polymerization of diacetone acrylamide (DAAm) in water using a $\omega$-bifunctional poly(ethylene glycol) (PEG) macro-CTA. ${ }^{[32]}$ The authors compared the morphologies obtained with those from a monofunctional macro-RAFT agent, yielding conventional PEG- $b$-PDAAm diblock 
copolymers, and demonstrated that the Y-shaped copolymer, PEG- $b$-(PDAAm) $)_{2}$, promotes the production of nano-objects with high-order morphologies through the formation of bulky hydrophobic segments. Moreover, other groups have also shown that the topology of the macroRAFT agent (linear $v s$. graft) has an impact on the resulting particle morphology (and that pendant graft structures are favorable to the formation of higher order morphologies). ${ }^{[15,33]}$ These examples clearly highlight the importance of the macromolecular architecture but the number of available studies, especially in pure water, are too limited for the elucidation of generic design rules. There is thus a need to perform deeper investigations in order to better understand the influence of the macromolecular architecture on morphologies obtained by PISA. Possible reasons for this lack in architectural diversity in PISA might be the more laborious synthesis of multi-functional RAFT agents ${ }^{[34-39]}$ and the difficulty in obtaining good polymerization control. ${ }^{[40,41]}$

In this communication, we study the influence of the macro-CTA architecture on the morphology of the self-assemblies obtained by aqueous RAFT dispersion polymerization in PISA, and compare amphiphilic diblock $(\mathrm{AB})$ and triblock $(\mathrm{AB})_{2}$ with triarm, star shaped copolymers $(\mathrm{AB})_{3}$. While amphiphilic $\mathrm{AB}$ and $(\mathrm{AB})_{2}$ copolymers have already been prepared by PISA in water, ${ }^{[23-31]}$ analogous triarm star copolymer $(\mathrm{AB})_{3}$ have not been reported, to the best of our knowledge. Poly( $N, N$-dimethylacrylamide) (PDMAc) and PDAAm were selected as the hydrophilic (A) and hydrophobic (B) blocks, respectively. PDMAc- $b$-PDAAm diblock copolymers have already been extensively studied in PISA and it has been shown that a large variety of morphologies is accessible via aqueous dispersion polymerization. For this system, quite complete phase diagrams have been established, ${ }^{[13,42-45]}$ but all of them for $\mathrm{AB}$ diblock copolymers only. Firstly, we described the synthesis of mono-, bi- and trifunctional CTAs primarily used to control the polymerization of $N, N$-dimethylacrylamide (DMAc). The resulting macro-CTAs were then chain-extended in the aqueous dispersion polymerization of 
DAAm, and the morphologies of the nano-objects obtained from the self-assembly of the linear PDMAc- $b$-PDAAm and (PDMAc- $b$-PDAAm $)_{2}$ series and the triarm star (PDMAc- $b$-PDAAm $)_{3}$ block copolymer were compared.

\section{Results and Discussion}

\subsection{Synthesis of the RAFT agents}

Monofunctional, bifunctional and trifunctional RAFT agents were synthesized according to the strategy displayed in Scheme S1 (see SI), starting from the same carboxylic acid functional RAFT agent (CTA-0), which was obtained by a procedure adapted from O'Reilly et al. ${ }^{[46]}$ By using our conditions, CTA-0 was conveniently obtained in good yield (91\%) (see SI) which is significantly higher than the one previously reported using other conditions $(29 \%) .{ }^{[47]}$ The corresponding ester, CTA-1 (Scheme 1a), was obtained by esterification reaction of CTA-0 with an excess of ethanol in presence of p-toluenesulfonic acid monohydrate (APTS) as catalyst. CTA-2 and 3 (Scheme 1a) were prepared in reasonable yields by reaction of CTA-0 with 1,6-hexanediol and 1,1,1-tris(hydroxymethyl)propane respectively (procedure adapted from Paek et al. ${ }^{[48]}$ ). The analytical data for the RAFT agents were consistent with the proposed structures (see SI, Figure S1, S2, S3 and S4).

\subsection{Poly( $N, N$-dimethylacrylamide) macro-RAFT agents, PDMAc-CTA-1, PDMAc-CTA- 2 and PDMAc-CTA-3}

The three new RAFT agents (CTA-1, CTA-2, CTA-3, Scheme 1a) with one, two or tri reactive trithiocarbonate (TTC) groups were subsequently used for the synthesis of different $\operatorname{poly}(N, N$ dimethylacrylamide) macromolecular RAFT agents (PDMAc macro-CTAs) (Scheme 1b). According to previously established protocols, ${ }^{[49]}$ the polymerizations of DMAc were conducted in $N, N$-dimethylformamide (DMF) at $70{ }^{\circ} \mathrm{C}$. 
(a)

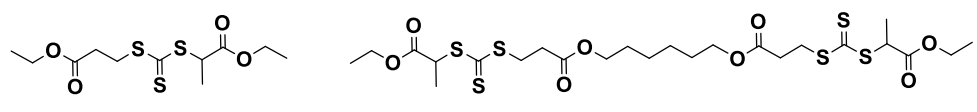

$$
\begin{aligned}
& \text { CTA-1 }
\end{aligned}
$$

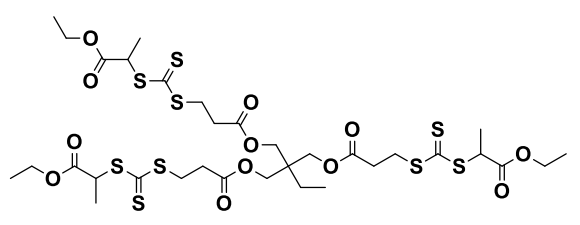

(b)

CTA-3

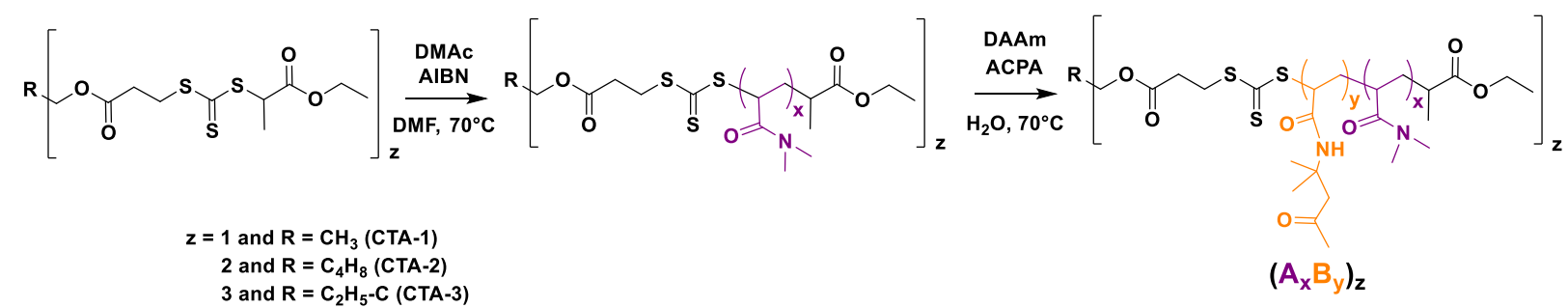

Scheme 1. (a) Structures of the three new RAFT agents used in this work. (b) Reaction scheme for the synthesis of PDMAc macro-RAFT agents and their subsequent chain extension with DAAm to produce of $\left(\mathrm{PDMAc}_{\mathrm{x}}-b-\mathrm{PDAAm}\right)_{\mathrm{z}}$ block copolymers via aqueous RAFT dispersion polymerization.

Size exclusion chromatography (SEC) analyses showed that polymers with low molar mass dispersity were formed with the three types of CTAs (see Table S1), and generally, the numberaverage molar masses determined by ${ }^{1} \mathrm{H}-\mathrm{NMR}, M_{\mathrm{n}, \mathrm{RMN}}$, (Table S1) were in good agreement with the theoretical values indicating that the number of chains was governed by the RAFT agent concentration; all analytical methods provided evidence for a controlled radical polymerization. As an example (shown in Table S1 and Figure S5A), the polymerization in presence of the trifunctional trithiocarbonate RAFT agent, CTA-3 proceeded rapidly and a relatively high monomer conversion (68\%) was reached after only $90 \mathrm{~min}$ (Table S1, Experiment P4). Moreover, RAFT polymerization exhibited pseudo-first order kinetics with a very short induction period (about $10 \mathrm{~min}$ ) (Figure S5A). SEC studies confirmed that the homopolymerization of DMAc was controlled as the growing polymer exhibited a linear increase of $M_{\mathrm{n}}$ with monomer conversion and dispersity $(\nexists)$ below 1.2 (Figure S5B, Table S1). Throughout the polymerization, SEC traces remained narrow and symmetrical in shape (Figure 
S6). Note that the trifunctional CTA structure - through the position of the R- and Z-groups gives rise to a convergent polymerization mechanism, also called core-first technique via Zgroup approach $^{[38]}$ for star polymers. This approach avoids the formation of higher-molar mass interstar coupling products. Such byproducts were indeed not observed by SEC analysis. Similar results were obtained for the polymerization of DMAc in presence of the bifunctional RAFT agent, CTA-2 (Table S1 and Figure S7 and S8). In conclusion, monofunctional, bifunctional and trifunctional PDMAc macro-CTAs of different molar masses could be prepared in a controlled fashion (Table S1) to be used in PISA.

\subsection{Preparation of amphiphilic copolymer nano-objects by PISA using mono-, bi- and trifunctional macromolecular RAFT agents}

As shown in Scheme 1, the different macro-RAFT agents were used in the aqueous dispersion polymerization of diacetone acrylamide (DAAm). Note that dispersion polymerizations are named MX, BX and TX to indicate the use of a monofunctional (M), bifunctional (B) and trifunctional (T) macro-CTA respectively. $x$ and $y$ designate the number-average degree of polymerization, $D P_{\mathrm{n}}$, of the PDMAc and PDAAm segments, respectively, within one arm (see Scheme 1). All polymerizations were performed at quite high monomer weight percentages (mostly at 19-20 wt\% of DAAm with respect to the total latex) and stable dispersions were obtained in all cases. In general, the monomer conversion increased rapidly and conversions > 90\% were reached within only $150 \mathrm{~min}$ (Table S2). The control over the polymer characteristics was investigated by SEC in DMF (+ $\left.\mathrm{LiBr} 1 \mathrm{~g} \mathrm{~L}^{-1}\right)$. As reported in Table $\mathrm{S} 2$ and in Figure 1 and S9, independently of the macro-RAFT agent architecture used, a complete shift of the initial PDMAc macro-RAFT agent signals towards higher molar masses was observed, indicating the livingness of the polymerizations and the formation of block copolymers. Moreover, in all cases 
dispersities $Ð$ below 1.5 were obtained, which is comparable to the dispersities reported in the literature for PDMAc- $b$-PDAAm AB diblock copolymers obtained by PISA. ${ }^{[42,43,44]}$
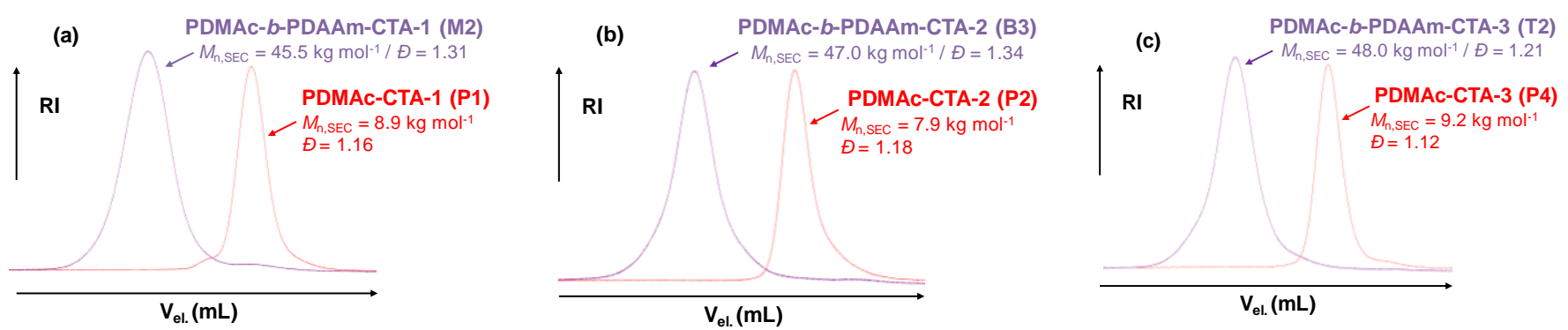

Figure 1. SEC chromatograms for block copolymers M2 (a), B3 (b) and T2 (c) (Table S2) prepared by dispersion polymerization of DAAm in water at $70{ }^{\circ} \mathrm{C}$ with monofunctional $(\mathrm{P} 1)$, bifunctional (P2) and trifunctional (P4) macro-CTAs respectively (Table S1).

The morphologies of the different block copolymer nano-objects were determined by transmission electron microscopy (TEM) (or cryo-TEM) (see Table S2). It has previously been reported that aqueous dispersion polymerization of DAAm in the presence of monofunctional PDMAc-macro-RAFT agents generated all sorts of particle morphologies, notably by varying the respective block lengths or the monomer concentration used in the PISA process. ${ }^{[13,42-45]}$ As complete phase diagrams have already been established for PDMAc- $b$-PDAAm AB diblock copolymers, in this work, we mainly focused on the morphological study of more complex PDMAc/PDAAm macromolecular architectures, $(\mathrm{AB})_{2}$ and $(\mathrm{AB})_{3}$. Interestingly, using bi- or trifunctional macro-CTAs (PDMAc-CTA-2 or 3) in similar conditions as those reported for the monofunctional macroRAFT, the formation of various morphologies could also be observed. As shown in the TEM images (Figure 2), in the presence of the bifunctional PDMAc-CTA-2 (Experiment $\mathrm{P} 2$, Table $\mathrm{S} 1$ ) with an overall $D P_{\mathrm{n}, \mathrm{PDMAc}}=108$ and $D P_{\mathrm{nPDMAc}} /$ arm $=x=54$, the particle morphology could be tuned from spheres to worms to vesicles by progressively increasing the molar mass of the PDAAm block (for $D P_{\mathrm{n}, \mathrm{PDAAm}} / \operatorname{arm}=y=27,92$ and 127, 
Experiment B1, B2 and B3, Table S2). However, as expected, ${ }^{[44]}$ using a very long PDMAc stabilizer (overall $\left.D P_{\mathrm{n}, \mathrm{PDMAc}}=169, D P_{\mathrm{n}, \mathrm{PDMAc}} / \mathrm{arm}=x=85\right)$ inhibited the formation of high order morphologies at comparable PDAAm block length (compare Experiment B3 and B4).

(a) $\mathrm{B} 1(y=27)$

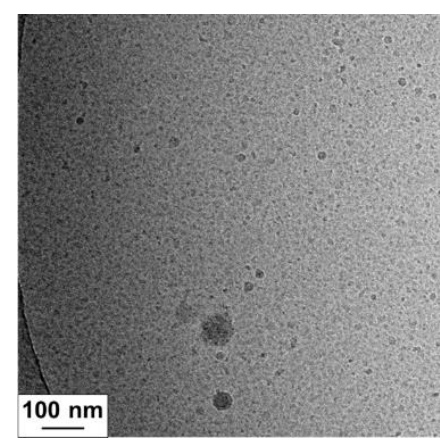

(e) B2bis $(y=92)$

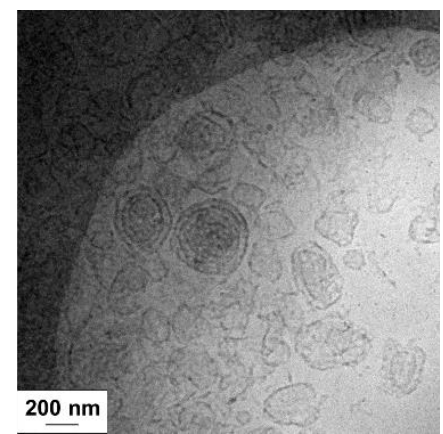

(b) B2 $(y=92)$

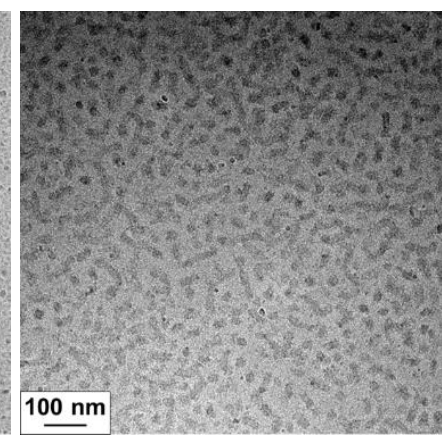

(f) $\mathrm{T} 1(y=61)$

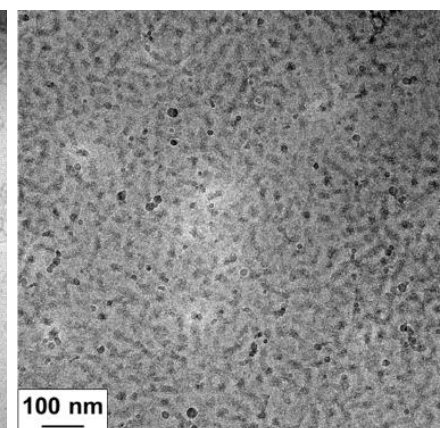

(c) B3 $(y=127)$

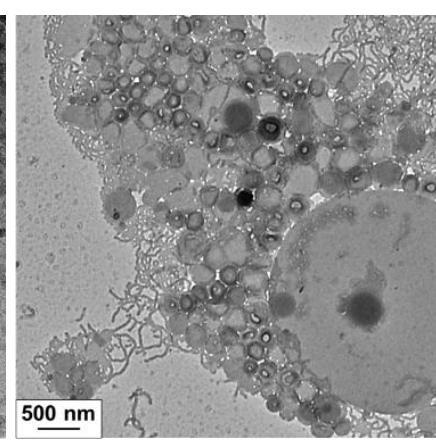

(g) T3 $(y=138)$

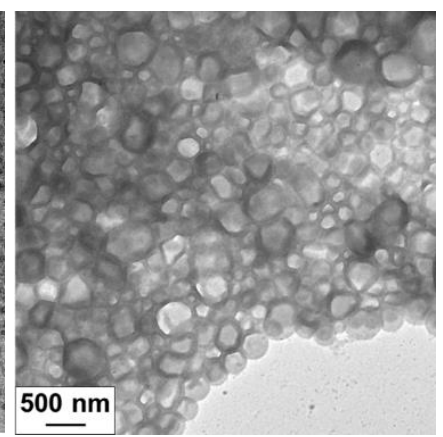

(d) B4 $(y=128)$

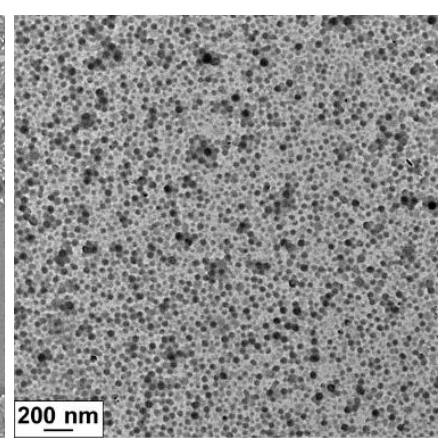

(h) T6 $(y=130)$

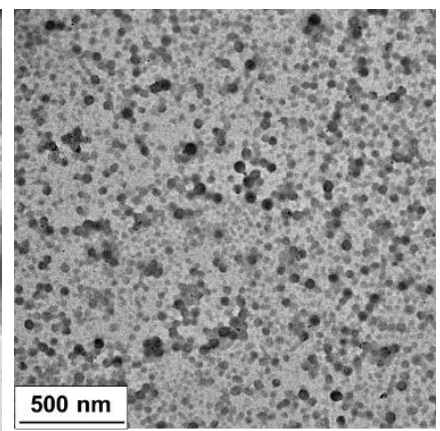

Figure 2. Representative transmission electron microscopy (TEM) images of (PDMAc $54-b$ $\left.\mathrm{PDAAm}_{y}\right)_{2}(\mathrm{AB})_{2}$ copolymer nano-objects prepared at room temperature (RT): (a) $y=27$ (cryoTEM); (b) $y=92$ (cryo-TEM) and (c) $y=127$ (Experiment B1, B2 and B3 in Table S2). (d) TEM image prepared at RT of (PDMAc $85-b$-PDAAm 128$)_{2}$ nano-objects (Experiment B4, Table S2). (e) CryoTEM image prepared at $60{ }^{\circ} \mathrm{C}$ of (PDMAc49- $b$-PDAAm92)2 nano-objects (Experiment B2bis, Table S2). TEM images of $\left(\mathrm{PDMAc}_{36} \text { or } 38-b \text {-PDAAm }\right)_{3}(\mathrm{AB})_{3}$ star copolymer nano-objects prepared at RT: (f) $y=61$ (cryo-TEM) and (g) $y=138$ (Experiment

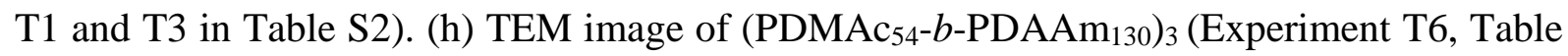
S2) prepared at RT. 
Interestingly, the $(\mathrm{AB})_{2}$ nano-objects underwent temperature-induced morphological transitions (TIMT). For instance, for the triblock copolymer (PDMAc $49-b$-PDAAm 92$)_{2}$, short worms were observed by TEM when the sample was prepared at $5{ }^{\circ} \mathrm{C}$ (Figure S10), whereas multilamellar vesicles were imaged for the sample prepared at $60{ }^{\circ} \mathrm{C}$ (Figure 2e). Such TIMT has already been reported for PDMAc- $b$-PDAAm AB diblock copolymers, ${ }^{[42,44]}$ but also for other types of diblock polymers prepared by aqueous dispersion polymerization in a PISA process. ${ }^{[9,50]}$ It was explained by the lower degree of hydration of the core-forming polymer block at higher temperature, which decreases the effective volume of the stabilizer block and hence increases the packing parameter $p$.

In presence of the shortest trifunctional PDMAc macro-CTA-3 with an overall $D P_{\mathrm{n}} \sim 110$ (and $D P_{\mathrm{n}, \mathrm{PDMAc}} / \operatorname{arm}=x \sim 37, \mathrm{P} 4$ and P5a in Table S1), short wormlike micelles were produced when relatively short PDAAm blocks were synthesized $\left(D P_{\mathrm{n}, \mathrm{PDAAm}} / \mathrm{arm}=y=61\right.$, T1 in Table S2, Figure 2f). Similarly to the linear triblock copolymers, increasing the hydrophobic volume through the increase of the hydrophobic block length resulted in the production of vesicles (Experiment T2 and T3 in Table S2, Figure S11 and 2g). Again, the formation of such higher order morphologies was inhibited when the overall $D P_{\mathrm{n}}$ of the stabilizer PDMAc was increased $\left(\mathrm{T} 6\right.$, overall $D P_{\mathrm{n}, \mathrm{PDMAc}}=163, D P_{\mathrm{n}, \mathrm{PDMAc}} /$ arm $\left.=x=54\right)$ while maintaining a similar $D P_{\mathrm{n}}$ for the PDAAm block $\left(D P_{\mathrm{n}, \mathrm{PDAAm}} / \mathrm{arm}=y=130\right)$ : only spheres were observed (compare $\mathrm{T} 3$ and T6 in Table S2, Figure 2h).

Similar to standard $\mathrm{AB}$ diblock copolymers, ${ }^{[42-45]}$ the morphology of $(\mathrm{AB})_{2}$ and $(\mathrm{AB})_{3}$ copolymers can thus be qualitatively described by the so-called packing parameter $p$ which predicts that the morphology obtained by amphiphilic block copolymers is dictated by the respective volume fractions of the hydrophilic and hydrophobic segments. Therefore, for a constant hydrophilic block length in a given copolymer system, the structure evolves from 
spherical micelles into worms and vesicles as the block length of the hydrophobic block is increased. The cartoon in Figure $\mathbf{S 1 2}$ proposes how $\mathrm{AB},(\mathrm{AB})_{2}$ and $(\mathrm{AB})_{3}$ block copolymers might be packed into the different morphologies.

We suppose that, independently of the macromolecular architecture (linear and star-shaped structures), a too long stabilizer block inhibits particle fusion - a prerequisite for the formation of higher order structures ${ }^{[51]}$ and therefore the formation of higher order structures. Consequently only kinetically trapped spherical morphologies are obtained. It should be added that the diameter of the spherical particles - determined by dynamic light scattering (DLS) was always in the range of $25-75 \mathrm{~nm}$ and increased with $D P_{\mathrm{n}, \mathrm{PDAAm}}$. The initial monomer / RAFT agent molar ratio, which determines the length of the hydrophobic block in a controlled radical RAFT polymerization system, clearly has a significant impact on the particle size (compare T4 to T6 for example in Table S3). ${ }^{[52,53,54]}$

\subsection{Influence of the macromolecular architecture on morphologies obtained by PISA}

In order to illustrate the effect of the macro-CTA architecture on the PISA morphologies, we firstly compared results obtained from amphiphilic copolymer with the same "arm" length $(x+y)$, i.e. $\mathrm{A}_{\mathrm{x}} \mathrm{B}_{\mathrm{y}},\left(\mathrm{A}_{\mathrm{x}} \mathrm{B}_{\mathrm{y}}\right)_{2}$ and $\left(\mathrm{A}_{\mathrm{x}} \mathrm{B}_{\mathrm{y}}\right)_{3}$. As mentioned in the introduction, PDMAc$c_{x}-b-\mathrm{PDAAm}_{y}$ diblock copolymers have already been extensively studied in PISA and quite complete phase diagrams have been established. Table S3 displays the results obtained by Armes et al. ${ }^{[44]}$ with PDMAc- $b$-PDAAm diblock copolymers $(\mathrm{AB})$ and those obtained in this work with our $(\mathrm{AB})_{2}$ linear triblock copolymer and triarm $(\mathrm{AB})_{3}$ star copolymers prepared in comparable polymerization conditions (at $70{ }^{\circ} \mathrm{C}$, comparable solids content, same initiating system). Comparing the linear $\mathrm{AB}$ diblock and $(\mathrm{AB})_{2}$ triblock copolymers at the same respective length of the arms (same $x$ and same $y$ ), similar morphologies were obtained even though symmetrical 
$(A B)_{2}$ copolymers might promote the production of nano-objects with high-order morphology: a mixture of spherical micelles and worms was obtained with a PDMAc58- $b$-PDAAm91 diblock copolymer (Experiment M3, Table S3), while mainly worms were observed with a (PDMAc54b-PDAAm92 $)_{2}$ (Experiment B2, Figure 2, Table S3). Similarly, a mixture of worms and vesicles was obtained for $\mathrm{AB}$ diblock PDMAc58- $b$-PDAAm 126 , while a majority of vesicles was clearly observed for (PDMAc ${ }_{54}-b$-PDAAm 127$)_{2}$ (Experiment M4 and B3, Table S3). On the other hand, comparison with the star shaped $(\mathrm{AB})_{3}$ copolymers revealed that only spheres were produced with the trifunctional macro-CTA possessing arms of equivalent $D P_{\mathrm{n}} / \operatorname{arm}(x=54)$. Indeed, $\left(\mathrm{PDMAc}_{54}-b \text {-PDAAm } 87\right)_{3}$ and $\left(\mathrm{PDMAc}_{54}-b \text {-PDAAm }{ }_{130}\right)_{3}$ triarm copolymers (T5 and T6 in Table S3) assembled into spherical micelles unlike their mono- or bifunctional counterparts. In this case, the hydrophilic part seems too large to promote nano-objects with high-order morphologies despite a long hydrophobic block and similar $x / y$ ratio. By decreasing the length of the hydrophilic block $x$ (from 54 to about 38), vesicles could be formed from the star-shaped $(\mathrm{AB})_{3}$ for a $D P_{\mathrm{n}}$ of the hydrophobic PDAAm block $(y)$ about 100 , while linear $\mathrm{AB}$ diblock copolymers (PDMAc40- $b$-PDAAm99) self-assembled into worms (compare T2 and M5 in Table S3).

When we compared copolymers on the basis of their total $D P_{\mathrm{n}}$ of PDMAc $(x \times z)$ and $D P_{\mathrm{n}}$ of PDAAm $(y \times z)$, i.e. comparable $x / y$ ratio (Table 1), we observed that the morphologies obtained for comparable linear $(\mathrm{AB})_{2}$ and star shaped $(\mathrm{AB})_{3}$ copolymers were very close. Indeed, short worms were mainly observed with $\left(\mathrm{PDMAc}_{54}-b-\mathrm{PDAAm}_{92}\right)_{2}$ and $\left(\mathrm{PDMAc}_{36}-b-\mathrm{PDAAm}_{61}\right)_{3}$ (compare B2 and $\mathrm{T} 1$ in Figures $2 \mathrm{~b}$ and $2 \mathrm{f}$ ), while vesicles were mainly observed with

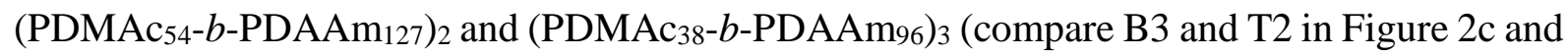
S11). However, only spheres were produced in the synthesis of their AB diblock copolymer counterparts (see Experiment M1 and M2, Table 1 and Figure S13). As explained above and 
in accordance with the literature, ${ }^{[44]}$ the hydrophilic segment is too large to allow the formation of non-spherical micelles. The same observation was made for the linear $(A B)_{2}$ and star structures $(\mathrm{AB})_{3}$ : when the overall $D P_{\mathrm{n}, \mathrm{PDMAc}}$ was increased from $\sim 110$ to $\sim 165$ and by targeting an overall $D P_{\mathrm{n}}$ of about 280 for the hydrophobic block, only spheres are also obtained (B4 and T5, Table 1 and Figure S14).

Table 1. Comparison of (PDMAc $\left.{ }_{x}-b-\mathrm{PDAAm}_{y}\right)_{z}$ morphologies exhibiting similar total $D P_{\mathrm{n}}$ of $\mathrm{A}(x \times z)$ and $D P_{\mathrm{n}}$ of $\mathrm{B}(y \times z)$ (and similar $x / y$ ratios).

\begin{tabular}{|c|c|c|c|c|c|c|c|c|}
\hline Expt. $^{\text {a) }}$ & $\begin{array}{l}\text { Composition } \\
\text { of }(A B)_{z}\end{array}$ & $z$ & $\begin{array}{c}\left(\mathbf{A}_{\mathbf{x}} \mathbf{B}_{\mathbf{y}}\right)_{\mathrm{z}} \\
x \times z\end{array}$ & $y \times z$ & $\begin{array}{c}x / y \\
\text { ratio }\end{array}$ & $\begin{array}{c}\tau^{\mathbf{b})} \\
{[\%]}\end{array}$ & $\begin{array}{c}\text { Assigned } \\
\text { Morphologyc) }\end{array}$ & $\begin{array}{c}\mathbf{D}_{\mathbf{z}}^{\text {DLS }} \\
{[\mathbf{n m}] /} \\
\boldsymbol{\sigma}^{\mathbf{d})}\end{array}$ \\
\hline M1 & PDMAc $110-b$-PDAAm 177 & 1 & 110 & 177 & 0.62 & 19.6 & $S$ & $\begin{array}{c}69 / \\
0.14\end{array}$ \\
\hline B2 & $\left(\text { PDMAc }_{54-b} b \text {-PDAAm92 }\right)_{2}$ & 2 & 108 & 184 & 0.59 & 19.5 & $\begin{array}{c}\text { sW } \\
(+ \text { few } S)\end{array}$ & $\begin{array}{l}212 / \\
0.24\end{array}$ \\
\hline T1 & $\left(\text { PDMAc }_{36}-b \text {-PDAAm } 61\right)_{3}$ & 3 & 108 & 184 & 0.59 & 19.5 & $\begin{array}{c}\text { sW } \\
(+ \text { few } S)\end{array}$ & $\begin{array}{c}67 / \\
0.20\end{array}$ \\
\hline M2 & PDMAc $110-b$-PDAAm 264 & 1 & 110 & 264 & 0.42 & 19.0 & $S$ & $\begin{array}{c}73 / \\
0.23\end{array}$ \\
\hline B3 & $\left(\text { PDMAc }_{54-b} b \text {-PDAAm } 127\right)_{2}$ & 2 & 108 & 253 & 0.43 & 19.3 & $\begin{array}{c}\mathrm{V} \\
(+\mathrm{W})\end{array}$ & $\begin{array}{l}289 / \\
0.38\end{array}$ \\
\hline $\mathbf{T} 2$ & $\left(\right.$ PDMAc $_{38}-b$-PDAAm96)3 & 3 & 115 & 290 & 0.40 & 19.9 & V & $\begin{array}{l}860 / \\
0.16\end{array}$ \\
\hline B4 & $($ PDMAc85-b-PDAAm128) & 2 & 169 & 255 & 0.66 & 19.7 & $S$ & $\begin{array}{c}56 / \\
0.07\end{array}$ \\
\hline T5 & $\left(\right.$ PDMAc $_{54-b} b$-PDAAm87)3 & 3 & 163 & 260 & 0.63 & 19.6 & $S$ & $\begin{array}{c}33 / \\
0.10\end{array}$ \\
\hline
\end{tabular}

${ }^{\text {d) }}$ For details refer to Table $\mathrm{S} 2 ;{ }^{\mathrm{b})} \tau=\mathrm{m}_{0}(\mathrm{DAAm}) / \mathrm{m}_{0}$ (total); ${ }^{\mathrm{c})}$ Determined by TEM studies of $0.1 \mathrm{wt} \%$ aqueous dispersion or cryo-TEM studies of $3 \mathrm{wt} \%$ aqueous dispersion. $\mathrm{S}=$ sphere, $\mathrm{W}$ $=$ worms, $\mathrm{sW}=$ short worms, $\mathrm{V}=$ vesicles; ${ }^{\mathrm{d})} D_{\mathrm{z}}$ is the Z-average particle diameter and $\sigma$ the dispersity factor derived from dynamic light scattering. 


\section{Conclusions}

In this study we investigated the influence of the macro-RAFT agent macromolecular architecture on PISA performed under aqueous dispersion conditions. Three novel RAFT agents of increasing complexity have been synthesized and used in the solution polymerization of DMAc to prepare mono-, bi- and trifunctional macro-RAFT agents. Independently of the RAFT agent architecture, the solution polymerizations were well controlled. The PDMAcmacro-CTA were then successfully tested in the aqueous dispersion polymerization of DAAm to form three types of amphiphilic PDMAc (A) / PDAAm (B) block copolymers: linear AB and $(\mathrm{AB})_{2}$ copolymers or triam star shaped $(\mathrm{AB})_{3}$ copolymers. The latter architecture was synthesized for the first time by PISA. High blocking efficiency and good polymerization control was observed for all series, although the more complex architectures yielded slightly higher molar mass dispersities. According to the PISA approach, the block copolymers selfassembled into particles. Depending on the length of the blocks, various morphologies were produced. The influence of the macro-CTA architecture on the morphology was studied by comparing amphiphilic $\mathrm{AB}$ diblock, $(\mathrm{AB})_{2}$ triblock and triarm star shaped $(\mathrm{AB})_{3}$ copolymers. Using the bi- or trifunctional macro-CTA, higher order morphologies (worms, vesicles) could be produced as long as the hydrophilic part was not too large, similar to what has been reported before for monofunctional macro-CTAs. ${ }^{[44]}$ By comparing copolymers with the same $A B$ "arm(s)" (same chemical nature and the same respective length of the blocks produced at the

same solids content), similar morphologies were obtained for amphiphilic $\mathrm{AB}$ and $(\mathrm{AB})_{2}$, while only spheres were obtained with the triarm $(\mathrm{AB})_{3}$ copolymers. The overall $M_{\mathrm{n}}$ of the PDMAc and the PDAAm segments at a comparable $M_{\mathrm{n}}(\mathrm{PDMAc}) / M_{\mathrm{n}}(\mathrm{PDAAm})$ ratio, rather than the individual length of the arms, was found to predetermine the morphologies for the linear $(\mathrm{AB})_{2}$ and star shaped $(\mathrm{AB})_{3}$ copolymers: very similar morphologies were obtained with $(\mathrm{AB})_{2}$ and 
$(\mathrm{AB})_{3}$ copolymer with similar overall $M_{\mathrm{n}}$ and A/B molar mass ratio. Currently, our work is directed towards the study of other complex RAFT agent structures in the use of PISA.

\section{Supporting Information}

Supporting Information is available from the Wiley Online Library or from the author.

Acknowledgements: J.R. thanks the Agence Nationale de la Recherche (PISAForFilms project, ANR-17-CE09-0031-01).

Received: Month XX, XXXX; Revised: Month XX, XXXX; Published online:

((For PPP, use "Accepted: Month XX, XXXX" instead of "Published online")); DOI: 10.1002/marc.((insert number)) ((or ppap., mabi., macp., mame., mren., mats.))

Keywords: PISA, aqueous RAFT dispersion polymerizations, triarm star copolymers, architectures, morphologies

\section{References}

[1] S. L. Canning, G. N. Smith, S. P. Armes, Macromolecules 2016, 49, 1985.

[2] U. Tritschler, S. Pearce, J. Gwyther, G. R. Whittell, I. Manners, Macromolecules 2017, $50,3439$.

[3] J. Chiefari, Y. K. Chong, F. Ercole, J. Krstina, J. Jeffery, T.P.T. Le, R. T. A. Mayadunne, G. F. Meijs, C. L. Moad, G. Moad, E. Rizzardo, S. H. Thang, Macromolecules 1998, 31, 5559.

[4] B. Charleux, G. Delaittre, J. Rieger, F. D'Agosto, Macromolecules 2012, 45, 6753.

[5] J.-T. Sun, C.-Y. Hong, C.-Y. Pan, Polym. Chem. 2013, 4, 873. 
[6] M. Lansalot, J. Rieger, F. D’Agosto, in Macromolecular Self-assembly, (Eds: L. Billon, O. Borisov), 1st ed., Wiley-VCH, Weinheim 2016, Ch. 2.

[7] e.g. D. Zhou, R.P. Kuchel, P. B. Zetterlund, Polym. Chem. 2017, 8, 4177.

[8] e.g. a) D. B. Wright, M. A. Touve, L. Adamiak, N. C. Gianneschi, ACS Macro Lett. 2017, 6, 925; b) L. Zhang, C. Song, J. Yu, D. Yang, M. Xie, J. Polym. Sci. Part A: Polym. Chem. 2012, 48, 5231.

[9] N. J. Warren, S. P. Armes, J. Am. Chem. Soc. 2014, 136, 10174.

[10] A. Blanazs, J. Madsen, G. Battaglia, A. J. Ryan, S. P. Armes, J. Am. Chem. Soc. 2011, 133,16581

[11] S. Y. Khor, N. P. Truong, J. F. Quinn, M. R. Whittaker, T. P. Davis, ACS Macro Lett. 2017, 6, 1013.

[12] D. Zhou, S. Dong, R. P. Kuchel, S. Perrier, P. B. Zetterlund, Polym. Chem. 2017, 8, 3082.

[13] C. A. Figg, R. N. Carmean, K. C. Bentz, S. Mukherjee, D. A. Savin, B. S. Sumerlin, Macromolecules 2017, 50, 935.

[14] X. Zhang, J. Rieger, B. Charleux, Polym. Chem. 2012, 3, 1502.

[15] J. Lesage de la Haye, X. Zhang, I. Chaduc, F. Brunel, M. Lansalot, F. D’Agosto, Angew. Chem. Int. Ed. 2016, 55, 3739.

[16] Y. Pei, K. Jarrett, L. G. Garces, M. Saunders, J.-P. Croue, P.J. Roth, C. E. Buckley, A. B. Lowe, $R S C A d v$ 2016, 6, 28130.

[17] J. M. Ren, T. G. McKenzie, Q. Fu, E. H. H. Wong, J. Xu, Z. An, S. Shanmugam, T. P. Davis, C. Boyer, G. G. Qiao, Chem. Rev. 2016, 116, 6743.

[18] C. Booth, D. Attwood, Macromol. Rapid Commun. 2000, 21, 501.

[19] C. Gao, S. Li, Q. Li, P. Shi, S. A. Shah, W. Zhang, Polym. Chem. 2014, 5, 6957. 
[20] X. Wang, J. Xu, Y. Zhang, W. Zhang, J. Polym. Sci. Part A: Polym. Chem. 2012, 50, 2452.

[21] W. Wang, C. Gao, Y. Qu, Z. Song, W. Zhang, Macromolecules 2016, 49, 2772.

[22] L. Yang, Q. Han, Q. Song, H. Li, Q. Zhao, Y. Shen, Y. Luo, Colloid. Polym. Sci. 2017, $295,891$.

[23] J. Rieger, W. Zhang, F. Stoffelbach, B. Charleux, Macromolecules 2010, 43, 6302.

[24] M. Chenal, L. Bouteiller, J. Rieger, Polym. Chem. 2013, 4, 752.

[25] C. J. Mable, K. L. Thompson, M. J. Derry, O. O. Mykhaylyk, B. P. Binks, S. P. Armes Macromolecules 2016, 49, 7897.

[26] Y. Luo, X. Wang, Y. Zhu, B-G. Li, S. Zhu, Macromolecules 2010, 43, 7472.

[27] A. J. Convertine, B. S. Lokitz, Y. Vasileva, L. J. Myrick, C. W. Scales, A. B. Lowe, C. L. McCormick, Macromolecules 2006, 39, 1724.

[28] C. J. Mable, L. A. Fielding, M. J. Derry, O. O. Mykhaylyk, P. Chambonb, S. P. Armes, Chem. Sci. 2018, 9, 1454.

[29] X. Fu, Y. Yuan, X. Chen, Y. Xiao, J. Wang, C. Zhou, J. Lei, J. Appl. Polym. Sci. 2017, $134,45379$.

[30] A. H. Milani, L. A. Fielding, P. Greensmith, B. R. Saunders, D. J. Adlam, A. J. Freemont, J. A. Hoyland, N. W. Hodson, M. A. Elsawy, A. F. Miller, L. P. D. Ratcliffe, O. O. Mykhaylyk, and S. P. Armes, Chem. Mater. 2017, 29, 3100.

[31] Z. Qiao, T. Qiu, W. Liu, L. Zhang, J. Tu, L. Guo, X. Li, Polym. Chem. 2017, 8, 3013.

[32] X. Wang, C. A. Figg, X. Lv, Y. Yang, B. S. Sumerlin, Z. An, ACS Macro Lett. 2017, 6, 337.

[33] S. Boissé, J. Rieger, K. Belal, A. Di-Cicco, P. Beaunier, M-H Lib, B. Charleux, Chem. Commun. 2010, 46, 1950. 
[34] C. Barner-Kowollik, in Handbook of RAFT Polymerization, Wiley VCH, Weinheim, Germany 2008.

[35] K. Belal, S. Poitras-Jolicoeur, J. Lyskawa, G. Pembouong, G. Cooke, P. Woisel, F. Stoffelbach, Chem. Commun. 2016, 52, 1847.

[36] C. Herfurth, P. Malo de Molina, C. Wieland, S. Rogers, M. Gradzielski, A. Laschewsky, Polym. Chem. 2012, 3, 1606.

[37] Y. K. Chong, T. P. T. Le, G. Moad, E. Rizzardo, S. H. Thang, Macromolecules 1999, 32, 2071.

[38] L. Barner, T. P. Davis, M. H. Stenzel, C. Barner-Kowollik, Macromol. Rapid Commun. 2007, 28, 539 .

[39] Y. Qu, X. Chang, S. Chen, W. Zhang, Polym. Chem. 2017, 8, 3485.

[40] A. M. Bivigou-Koumba, J. Kristen, A. Laschewsky, P. Müller-Buschbaum, C. M. Papadakis, Macromol. Chem. Phys. 2009, 210, 565.

[41] M. H. Allen, Jr., S. T. Hemp, M. Zhang, M. Zhang, A. E. Smith, R. B. Moorea, T. E. Long, Polym. Chem. 2013, 4, 2333.

[42] X. Wang, J. Zhou, X. Lv, B. Zhang, Z. An, Macromolecules 2017, 50, 7222.

[43] W. Zhou, Q. Qu, Y. Xu, Z. An, ACS Macro Lett. 2015, 4, 495.

[44] S. J. Byard, M. Williams, B. E. McKenzie, A. Blanazs, S. P. Armes, Macromolecules 2017, 50, 1482.

[45] L. Zhang, Q. Lu, X. Lv, L. Shen, B. Zhang, Z. An, Macromolecules 2017, 50, 2165.

[46] J. Skey, R. K. O’Reilly, Chem. Commun. 2008, 4183.

[47] K. Stokes, F. L. Beyer, Polymer Preprints 2010, 51, 709.

[48] K. Paek, S. Chung, C.-H. Choa, B. J. Kim, Chem. Commun. 2011, 47, 10272.

[49] L. Sambe, K. Belal, F. Stoffelbach, J. Lyskawa, F. Delattre, M. Bria, F. X. Sauvage, M. Sliwa, V. Humblot, B. Charleux, P. Woisel, Polym. Chem. 2014, 5, 1031. 
[50] N. P. Truong, C. Zhang, T. A. H. Nguyen, A. Anastasaki, M. W. Schulze, J. F. Quinn, A. K. Whittaker, C. J. Hawker, M. R. Whittaker, T P. Davis, ACS Macro Lett. 2018, 7, 159.

[51] J. Rieger, Macromol. Rapid Commun. 2015, 36, 1458.

[52] N. P. Truong, M. V. Dussert, M. R. Whittaker, J. F. Quinn, T. P. Davis, Polym. Chem. 2015, 6, 3865 .

[53] W. Zhang, F. D’Agosto, O. Boyron, J. Rieger, B. Charleux, Macromolecules 2011, 44, 7584.

[54] J. Rieger, F. Stoffelbach, C. Bui, D. Alaimo, C. Jérôme, B. Charleux, Macromolecules 2008, 41, 4065 . 